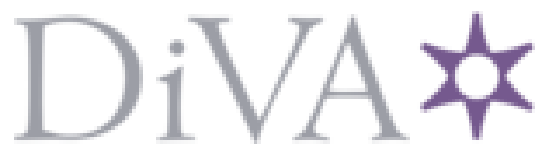

http://www.diva-portal.org

This is the published version of a paper published in Acta Anaesthesiologica Scandinavica.

Citation for the original published paper (version of record):

Bjornestad, E E., Haney, M. (2020)

An obstetric anaesthetist: A key to successful conversion of epidural analgesia to surgical anaesthesia for caesarean delivery?

Acta Anaesthesiologica Scandinavica, 64(2): 142-144

https://doi.org/10.1111/aas.13493

Access to the published version may require subscription.

N.B. When citing this work, cite the original published paper.

Permanent link to this version:

http://urn.kb.se/resolve?urn=urn:nbn:se:umu:diva-165623 


\section{An obstetric anaesthetist-A key to successful conversion of epidural analgesia to surgical anaesthesia for caesarean delivery?}

Managing an emergency caesarean section patient (C-section) is a challenging aspect of obstetric anaesthesia practice. The urgency of delivery can influence the mode of anaesthesia due to short time limits from decision to delivery. Given widely recognized risks associated with general anaesthesia and urgent/emergent C-section, how often can one safely manage the parturient with regional anaesthesia? Is this an expected result of subspecialty training, to more aggressively use regional anaesthesia in this setting? While spinal anaesthesia has gained wide acceptance, even with limited time frame goals from decision to delivery, epidural anaesthesia should be used when labour analgesia has been established prior to an emergency C-Section. The use of general anaesthesia may be reduced if the anaesthesiologist attending the emergency $\mathrm{C}$-section is an obstetric anaesthetist as opposed to a non-specialist. ${ }^{1}$ These are the questions explored in the report by Wagner et $\mathrm{al}^{1}$ in this month's issue of Acta Anaesthesiological Scandinavica.

Avoiding general anaesthesia or implementing regional anaesthesia in emergency deliveries is presumed to decrease risk of unwanted intraoperative awareness, the risk of hypoxia related to general anaesthesia and with failed intubation or aspiration of gastric contents into the lung. Employing regional anaesthesia is also widely accepted to be favourable concerning relatively less post-operative pain. Activating an epidural catheter placed for labour can provide surgical anaesthesia although this requires time, which might be limited given the agreed time from decision to delivery. From the patient's perspective, parturients commonly prefer to be awake when giving birth, either vaginally or surgically and as anaesthesiologists we must try to ensure a positive experience possible also in an emergency $\mathrm{C}$-section. Previous negative experience of pregnancy and childbirth contributes most to the fear of future childbirths in parous women. $^{2}$

Some anaesthesiologists strongly favour discontinuation of the epidural drug administration and induce a spinal anaesthesia, even if the labour analgesia is well functioning. The reason is usually that an epidural surgical quality blockade cannot be achieved in due time for an emergency surgical delivery, and general anaesthesia has much more rapid and reliable onset, although there is little or no evidence from the literature to support these statements. The statement is in contrast to the Royal College of Anaesthetist's published guidelines for best practice providing anaesthesia in emergency Caesarean deliveries. ${ }^{3}$ They suggest that an acceptable rate of general anaesthesia in a parturient receiving labour epidural analgesia should be no more than $3 \% .{ }^{3}$ According to the National Institute for Health and Care Excellence guidelines in the UK, general anaesthesia should be used in less than $1 \%$ in elective $\mathrm{C}$-sections and less than $5 \%$ in emergency C-sections. ${ }^{4}$

To achieve the recommended frequencies of neuraxial blockade in surgical deliveries, conversion of an ongoing labour epidural should be a first choice of anaesthetic technique. The quality of labour epidural may be important in order to obtain a successful conversion to surgical anaesthesia. However, risk factors for a failed labour epidural top-up are not uniformly defined in the literature yet well understood. Most commonly reported include prolonged duration of analgesia, the number of needed breakthrough or clinician bolus doses, a traditional epidural technique as compared to combined spinal/epidural (CSE) labour analgesia, tall patient stature, epidural catheter placement by a non-anaesthesia specialist, urgency of C-section and maternal obesity. ${ }^{4-10}$ No information was presented in the report from Wagner et al about the duration or quality of labour analgesia before the emergency C-section. ${ }^{1}$

These studies describing epidural conversion 'failure' have been observational and retrospective, and are subject to biases and confounders which have an effect on interpretation. Although the CSE has proven to be highly reliable for labour analgesia, there is no strong evidence yet to demonstrate that epidural catheters placed as part of a CSE ensures a higher success rate when converted to anaesthesia for delivery. ${ }^{10,11}$ In a systematic review and meta-analysis from Bauer et al, ${ }^{12}$ only three risk factors were associated with failure to convert an ongoing labour epidural to anaesthesia: the number of clinician bolus doses due to break-through pain, parturients taken care of by non-obstetrical anaesthetists, and the urgency of Csection. These findings were confirmed in later studies showing that epidural catheter is more likely to be used if a specialist in obstetric anaesthesia is the attending doctor for a surgical delivery. ${ }^{13}$ Riley et al showed that epidural analgesia in parturients initiated by non-obstetrical anaesthetists was associates with a lower success rate for adequate surgical anaesthesia. In that series, neuraxial labour analgesia performed by obstetric anaesthesiologists had a $2.9 \%$ failure 
rate compared to $11.8 \%$ with the non-OB anaesthesia specialist group. ${ }^{10}$ A study from Campbell et al reported a series with an incidence of general anaesthesia in this setting of $5.5 \%$ for the non-OB anaesthesia specialist group and $1.2 \%$ when obstetric anaesthetist managed the case. ${ }^{14}$ The results from Wagner et al did not formally test if a non-obstetric anaesthesiologist contributed to a higher risk of general anaesthesia, since there was no prospective control over which anaesthesiologist (and training) treated the patient, where randomisation to obstetric anaesthesia fellowship training exposure or not might mitigate a lot of potential bias or confounding related to the anaesthesia factor. However, the observational analysis found that presence of an obstetric fellowship trained anaesthesiologist was associated with a decreased rate of general anaesthesia (GA) use in patients with pre-existing labour epidural catheters when an emergency $\mathrm{C}$-section is needed, at least in that cohort. ${ }^{1}$

There is not a simple explanation why the overall epidural catheter failure rate seems much lower and the success rate of epidural conversion much higher when managed by obstetric anaesthesiologists. ${ }^{9,13,15}$ A better epidural technique in experienced and skilled hands presumably would be expected to reduce the risk of failure in general, although epidural catheter placement expertise also is found outside of obstetrical anaesthesia. Success has also to do with dosing and evaluating the clinical effects, as well as optimally preparing the patient. Higher success rates can only partially be explained by the differences in technique or technical skills. Dedicated anaesthesia staff at the delivery unit, being familiar with the progress of labour, will have early warnings if an epidural is inadequate and need optimization. An obstetric anaesthetist will closely monitor the parturient, diagnose if there are multiple clinician boluses or the reason for the breakthrough pain and target the problem. They will, if needed, replace the catheter in a timely fashion where a catheter and infusion are not optimally functioning, to be prepared to facilitate a safe conversion from analgesia to surgical anaesthesia if needed.

A well-functioning catheter in place is necessary in order to avoid general anaesthesia when there are time limitations. Palanisamy et al showed in their retrospective review a low rate of Caesarean deliveries needing general anaesthesia based on an aggressive replacement of suboptimal functioning epidural catheters. ${ }^{15}$ An obstetric anaesthetist specialist may also pull the epidural catheter by $1 \mathrm{~cm}$ before anaesthesia increasing the success rate converting the epidural analgesia to anaesthesia. ${ }^{10,14}$ Close communication with the obstetric team identifying those parturients most likely to require a C-section may reduce the risks of unsuccessful epidural top-ups. Dedicated staff also ensures immediate availability for emergency caesarean delivery. ${ }^{16}$

The urgency of caesarean delivery can be a risk factor for failed conversion to surgical anaesthesia, that is that clinicians give up on an epidural blockade that has not yet taken full effect. Still, women presenting for an emergency $\mathrm{C}$-section should be offered neuraxial anaesthesia in order to reduce the risks of neonatal and/ or maternal complications. The ideal decision-to-incision interval (DDI) or decision-to-delivery interval (DDD) remain controversial. No solid evidence of increased neonatal morbidity has emerged despite many institutions failing to achieve the universal 30-minute standard. ${ }^{17}$ Anaesthetist often argue that using a GA is much faster than an epidural top-up and at least in the most imminent situations GA should be preferred although there is no evidence to confirmed this statement in the literature. ${ }^{18}$ However, if topping up an epidural in situ is an option, some additional aspects must be considered. The time required to prepare for an emergency $\mathrm{C}$ section may be influenced by the epidural anaesthetic solution chosen. The ideal anaesthetic solution should allow fast, predictable and reliable extension of labour epidural analgesia to a block suitable for C-section. In the meta-analysis from Hillyard evaluating solutions to convert labour epidural analgesia to surgical anaesthesia, lidocaine $20 \mathrm{mg} / \mathrm{mL}$ with epinephrine and fentanyl was the fastest onset solution for caesarean delivery. ${ }^{19}$ Adding sodium bicarbonate to the lidocaine solution can reduce onset time even further. Earlier studies have disputed if lidocaine $20 \mathrm{mg} / \mathrm{mL}$ has a faster onset than both bupivacaine $5 \mathrm{mg} / \mathrm{mL}$ or ropivacaine (7.5 mg/mL). ${ }^{20}$ However, Hillyard concluded lidocaine to be fastest and bupivacaine and levobupivacaine $(5 \mathrm{mg} / \mathrm{mL})$ were the least effective. ${ }^{19} \mathrm{~A}$ better quality was observed when using ropivacaine $7.5 \mathrm{mg} / \mathrm{mL}$. The use of $30 \mathrm{mg} / \mathrm{mL}$ 2-chloroprocaine did not meet the inclusion criteria in this review. However, 2-chloroprocaine has shown to induce a rapid and a reliable onset of anaesthesia and can be used if available. ${ }^{20}$

Another important issue when a pre-existing block is extended for $\mathrm{C}$-section can be the compromise between avoiding systemic toxicity or an excessively high block on the one hand, and minimizing delay on the other hand. Transportation from labour ward to operating theatre is often the main reason for the time delay from decision to incision. To shorten the DDI interval the injection of the anaesthetic solution may start in the labour room. ${ }^{21-23}$ Inserting small boluses of the anaesthetic solution before patient transport (eg $5 \mathrm{~mL}$ ) followed by another bolus on arrival in the operating theatre is safe in the context with dedicated staff including an obstetric anaesthetist. A high or total spinal requiring intubation and ventilation is unlikely to occur if the top-up is administered after a previously well-established epidural block. Early detection of a subdural placed epidural catheter is ensured with close monitoring of the parturient and an ongoing communication with the obstetrician and midwifes.

In summary, an obstetric anaesthetist specialist can reduce the risk of delaying a category 1 caesarean delivery by continuously and carefully assessing the women with labour epidural and closely communicating with the obstetrician. Recognizing the risk for both conversion failures and if an emergency delivery is imminent, a specialist can guide towards a successful epidural anaesthesia by acting early and appropriately, and this requires experience, and confidence in this routing. This is experience acquired through immersion in obstetric anaesthesia. When emergencies occur, transportation often takes most of the DDI time interval. A specialist may start the top-up of a labour epidural in the labour room and before arriving in the operation theatre shortening the time to adequate anaesthesia. Knowledge of local protocols and logistics are fundamental to manage obstetric emergencies. Although the $5 \%$ level of failed conversion may be 
difficult to achieve generally, this may be an important inspiration for future prospective studies. Focusing on the standardization of our methods may be an important factor to increase the success of converting labour epidurals to anaesthesia in emergency deliveries.

Elin eb Bjornestad ${ }^{1}$

Michael F. Haney ${ }^{2}$

${ }^{1}$ Kirurgisk serviceklinikk, Klinikkoverlege, Helse Bergen HF, Norway

${ }^{2}$ Anesthesia and Intensive Care Medicine, University Hospital of Umeå, Umeå University, Umea, Sweden

Correspondence

Elin eb Bjornestad, Kirurgisk serviceklinikk, Klinikkoverlege, 5021 Haukeland Sykehus, Helse Bergen HF 5231, Norway. Email: elin.bjornestad@gmail.com

\section{ORCID}

Elin eb Bjornestad (iD https://orcid.org/0000-0002-8420-9367

Michael F. Haney (iD https://orcid.org/0000-0002-4049-8910

\section{REFERENCES}

1. Wagner J, White R, Mauer E, Pryor K, Kjaer K. Impact of Anesthesiologist's Fellowship status and experience on the risk of general anesthesia for Cesarean delivery in patients receiving labor epidural analgesia. Acta Anaesthesiol Scand. 2019;63(6):769-774.

2. Jolly J, Walker J, Kalvinder BK. Subsequent obstetric performance related to primary mode of delivery. Br J Obstet Gynaecol. 1999;106:227-232.

3. Russell IF. Technique of anaesthesia for caesarean section. In: Russell IF, ed. Raising the Standard: A compendium of Audit Recipes, 2nd edn. London, UK: Royal College of Anaesthetists; 2006:166-167.

4. Purva M. Cesarean section anesthesia: technique and failure rate. In: Colvin JR, Peden CJ, eds. Raising the Standard: A Compendium of Audit Recipes for Continuous Quality Improvement in Anaesthesia, 3rd edn. London, UK: Royal College of Anaesthetists; 2012:220.

5. Kinsella SM. A prospective audit of regional anaesthesia failure in 5080 Caesarean sections. Anaesthesia. 2008;63:822-832.

6. Pan PH, Bogard TD, Owen MD. Incidence and characteristics of failures in obstetric neuraxial analgesia and anaesthesia: a retrospective analysis of 19,259 deliveries. Int J Obstet Anesth. 2004;13:227-233.

7. Halpern SH, Soliman A, Yee J, Angle P, loscovich A. Conversion of epidural labour analgesia to anaesthesia for caesarean section: a prospective study of the incidence and determinants of failure. $\mathrm{Br} J$ Anaesth. 2009;102:240-243.
8. Orbach-Zinger S, Friedman L, Avramovich A. Risk factors for failure to extend labor epidural analagesia for Caesarean section. Acta Anaesthesiol Scand. 2006;50:793-797.

9. Tortosa JC, Parry NS, Mercier FJ, Mazoit JX, Benhamou D. Efficacy of augmentation of epidural analgesia for Caesarean section. $\mathrm{Br} J$ Anaesth. 2003;11:532-535.

10. Riley ET, Papasin J. Epidural catheter function during labor predicts anesthetic efficacy for subsequent caesarean delivery. Int J Obstst Anesth. 2002;11:81-84.

11. Norris MC. Are combined spinal-epidural catheters reliable? Int J Obstst Anesth. 2000;9:3-6.

12. Bauer ME, Kountanis JA, Tsen LC, Greenfield ML, Mhyre JM. Risk factors for failed conversion of labor epidural analgesia to caesarean delivery anaesthesia: a systematic review and meta-analysis of observational trials. Int J Obstet Anesth. 2012;21:294-309.

13. Gambling D, Berkowitz J, Farell TR, Pue A, Shay D. A randomised controlled comparison of epidural analgesia and combined spinal-epidural analgesia in a private practice setting: pain scores during first and second stages of labor and delivery. Anesth Analg. 2013;116:636-643.

14. Cambell DC, Tran T. Conversion of labor epidural analgesia to anesthesia for intrapartum Caesarean delivery. Can J Anaesth. 2009;56:19-26.

15. Palanisamy A, Mitani AA, Tsen LC. General anaesthesia for caesarean delivery at a tertiary care hospital from 2000-2005: a retrospective analysis and 10 years update. Int J Obstet Anesth. 2011;20:10-16.

16. Levy DM. Emergency Caesarean section: best practice. Anaesthesia. 2006;61:786-791.

17. Palmer E, Ciechanowicz S, Reeve A, Harris S, Wong DJN, Sultan $P$. Operating room-to-incision interval and neonatal outcome in emergency caesarean section: a retrospective 5-year cohort study. Anaesthesia. 2018;825-831.

18. Popham P, Buettner A, Mendola M. Anaesthesia for emergency caesarean section, 2000-2004, at the Royal Women's Hospital, Melbourne. Anaesth Intensive Care. 2007;35:74-79.

19. Hillyard SG, Bate TE, Corcoran TB, Paech MJ, O'Sullivan G. Extending epidural analgesia for emergency caesarean section:a meta-analysis. Br J Anaesth. 2011;107:668-678.

20. Gaiser RR, Cheek TG, Gutsche BB. Epidural lidocaine versus 2-chloroprocaine for fetal distress requiring urgent cesarean section. Int J Obstet Anesth. 1994;3(4):208-210.

21. Regan KJ, O'Sullivan G. The extension of epidural blockade for emergency Caesarean section: a survey of current UK practice. Anaesthesia. 2008;63:136-142.

22. Rafi MA, Arfeen Z, Misra U. Conversion of regional to general anaesthesia at caesarean section: increasing the use of regional anaesthesia through continuous prospective audit. Int Journal of Obstet Anesth. 2010;19:179-182.

23. McClure JH, Cooper GM, Clutton-Brock TH. Saving Mothers' Lives: reviewing maternal deaths to make motherhood safer: 2006-8: a review. Br J Anaesth. 2011;107(2):127-132. 